\title{
Referencing and borrowing from other systems: the Hong Kong education reforms
}

\author{
Katherine Forestier ${ }^{\mathrm{a}}$, Bob Adamson ${ }^{\mathrm{b}},{\text { Christine } \operatorname{Han}^{\mathrm{c}} \text { and Paul Morris }}^{\mathrm{c}}$ \\ ${ }^{a}$ Centre for Lifelong Learning Research \& Development, Hong Kong institute of Education, and Graduate school of

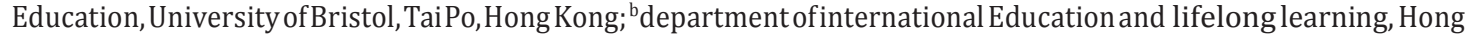 \\ Kong institute of Education, Tai Po, Hong Kong; cdepartment of Education, Practice and Society, UCL Institute of Education, \\ London, UK
}

To cite this article: KatherineForestier, BobAdamson, ChristineHan \& Paul Morris (2016): Referencing and borrowing from other systems: the Hong Kong education reforms, Educational Research, DOI: 10.1080/00131881.2016.1165411

To link to thisarticle: $\underline{\text { http://dx.doi.org/10.1080/00131881.2016.1165411 }}$

\begin{abstract}
Background: This paper analyses the role of, and approach to, policy referencing and borrowing in Hong Kong's recent reforms that culminated in the creation of its New Academic Structure and the Hong Kong Diploma of Secondary Education.

Main argument: It argues that Hong Kong has gone further than most jurisdictions not just in responding to global influences on education reform, but in taking explicit steps to internationally benchmark its curriculum and assessment, and in involving the global community at multiple levels in the process of education policy planning and implementation.

Sources of evidence and method: The paper is based on the documentary analysis of policy documents in Hong Kong, and 23 interviews with key stakeholders in the policy network, including policy-makers, practitioners and community leaders.

Discussion and conclusions: While policy referencing and borrowing in the Hong Kong context can, in part, be traced to a colonial legacy, the Special Administrative Region of China demonstrates a collaborative approach to education reform involving local and international engagement that may be relevant to other systems. Its approach was informed by a measured use of policy referencing that involved 'horizon scanning' of other systems' policies and practices; international benchmarking; and engaging international expertise to facilitate implementation.
\end{abstract}

\section{Introduction}

The strong performance of East Asian education systems in international tests such as the Organisation for Economic Co-operation and Development's (OECD) Programme for International Student Assessment (PISA) and the International Association for the Evaluation of Educational Achievement's (IEA) Trends in International Mathematics and Science Study (TIMSS) and Progress in International Reading Literacy Study (PIRLS) has attracted increasing interest from policy-makers in Western education systems to reference or borrow features believed to explain their success (Alexander 2012; Forestier and Crossley 2015; Morris 2015; Han 2016), with Hong Kong one of the 'high performing' reference systems (OECD 2014).

Despite its high ranking in the international testing arena since the 1980s, Hong Kong embarked on successive education reforms from the 1990s. From 2000, these involved a new curriculum ('Learning to Learn') and culminated in the launch of a New Academic Structure and new school leaving qualification, the Hong Kong Diploma of Secondary Education (HKDSE). From the outset of these reforms, Hong Kong policy-makers indicated that they would engage extensively in what can be seen as forms of policy referencing or borrowing. 'Policy borrowing' (Phillips and Ochs 2003),'policy learning' (Raffe and Spours 2007),'educational transfer' (Perry and Tor 2009) and 'referencing' (Steiner-Khamsi 2002) 
are some of the terms used to describe the interest policy-makers have long shown in importing policies and practices from elsewhere that they perceive to be more successful than their own, or to inform educational development and reforms. Referencing can involve genuine interest in learning from others, or mere rhetoric to justify policy decisions. We argue that it can be distinguished from'borrowing' when no actual policy or practice is borrowed or transferred, although it may influence the local solutions. The Hong Kong approach we identify thus involves a mix of referencing and borrowing.

Trends in referencing and attempts at explicit borrowing have increased sharply in recent decades (Sellar and Lingard 2013; Auld and Morris forthcoming). For example, Michael Gove, the former Secretary of State for Education under the UK's Conservative-led coalition government, initiated a number of international studies of systems that performed well in inter- national tests to inform curriculum and assessment reforms. Gove (2012) declared in a speech that the 2010 schools White Paper - The Importance of Teaching (Department for Education 2010) was designed to 'shamelessly plunder' from highperforming systems, which included Hong Kong. In addition, the expert panel for the Review of the National Curriculum in England compared curriculum source materials - what was taught at particular stages - from a number of countries (Department for Education 2011; Oates 2013), while the UK's Office of Qualifications and Examinations Regulations (Ofqual) conducted a comparison of their assessments (Ofqual 2012).

These trends have been explained as a reflection of the impact of globalisation, including common challenges facing countries within the global economy, the speed of information shared across the world, the growing network of educational expertise and the increasing quest to evaluate systems through international tests such as PISA (Crossley and Watson 2003; Meyer and Benavot 2013). Among the main purposes of international referencing in the contemporary context have been to identify, initiate and legitimise education reform, to secure a competitive edge (Waldow 2012; Kamens 2013; Morris 2015).

\section{Purpose}

This paper identifies and analyses the processes of policy referencing and borrowing which informed the recent education reforms in Hong Kong. While there is a substantial literature analysing patterns of policy borrowing/referencing in countries attempting to improve their performance on cross-national tests (e.g. Germany, Sweden, England and USA), there is a dearth of literature on the processes adopted in the high-performing East Asian societies.

This article examines what can be seen as examples of policy referencing and borrowing at different levels of the reform process that operated in Hong Kong. It will analyse how policy referencing was used to inform reforms, how international student assessments were employed as a reference to monitor learning outcomes and how other international bench- marking exercises were designed to influence, and secure public confidence in, a new curriculum and assessment. The article goes on to examine the roles of the various local and international actors involved, and identifies potential lessons from the Hong Kong approach to referencing and borrowing for other systems.

\section{Methodology}

This article is based on an analysis of Hong Kong policy documents and discourse since its return to Chinese sovereignty in 1997, as well as semi-structured interviews in Hong Kong. Twenty-three interviewees were purposefully selected to include a range of stakeholders in the policy network. The concept of a policy network draws on the work of Ozga (2000), Vidovich (2007) and Ball (2008) who describe how bureaucratic governance, including that of education, has shifted to governance 'in and by networks' of policy communities. This is 
helpful for understanding the complexities involved in policy development and implementation in Hong Kong, and for identifying the range of stakeholders relevant for this study.

The interviewees included policy-makers within government, past and present; senior members of policy advisory bodies such as the Education Commission (EC) and Curriculum Development Council (CDC); a former senior leader of the independent Hong Kong Examinations and Assessment Authority (HKEAA); school principals active in the various advisory and principal representative bodies; elected representatives for the education sector in the Legislative Council; and a number of overseas educationalists employed within the policy bodies or who acted as consultants during the planning and implementation of the reforms.

The interviews were conducted in English between December 2013 and June 2014, following ethical protocols required by the UCL Institute of Education, London; Hong Kong Institute of Education; and University of Bristol. Prior to the interviews, informed consent was gained from all participants, and their anonymity assured. Questions asked included the following:

- From your experience, how important do you think external referencing has been in education policy-making and attempts to drive school improvement and reform in Hong Kong, over the last 20 years?

- What have been the key features borrowed? How were these adapted and implemented, and how successfully have these been implemented? What have been the problems in trying to implement these?

- How influential have the PISA, TIMSS and PIRLS studies been for (a) informing understanding about the state of education in Hong Kong and (b) identifying new policy directions? What other sources of evidence are influential?

- How has their influence changed over time? What are your views on the value of this influence?

Interview data was analysed for emerging themes, using the 'Framework' approach devised by Ritchie and Spencer (1994) for applied policy research. Their five-stage process adapted for the study included familiarisation; identifying a thematic framework; indexing; charting; and mapping; and interpretation of data. This enabled us to compare and contrast perceptions from a wide range of stakeholders, with predominant views discerned based on the frequency with which they occurred in the various data sources.

\section{Historical context}

Prior to its recent reforms, Hong Kong had a long legacy of policy and cultural borrowing during 150 years of colonial rule. Much of its education system was based on a British model, albeit adapted over time to the local context to involve a synthesis between Western and Chinese features (Adamson and Li 2004; Sweeting 2004). Its structures were largely Western - specifically British, but also drawn from other commonwealth countries in the later years of colonialism. Examples of British influence include its grammar-school style curriculum, public examinations derived from and benchmarked to GCE Ordinary and Advanced Levels, textbooks largely produced by UK publishers, a major role for churches in running schools and promotingreligious education, an academicstructureatsecondary school level leading to public examinations after secondary years 5 and 7 , and the dominance of the English language as the medium of instruction. Through transnational education, British universities contributed extensively to teacher education and professional development, first at under- graduate level and later at Master's and Doctoral levels. Significant numbers of academics from the UK (and other commonwealth countries) were also situated locally (Forestier 2011). For some critics of colonialism, the 
imposition of colonial languages, curricula, examinations, textbooks and universities created a dependency culture that reflected a form of cultural borrowing (Crossley and Watson 2003). In the case of Hong Kong, however, Adamson and Li (2004) argue that colonial powers and the local educators they collaborated with adapted schooling to suit local contexts, and many locally based scholars such as Watkins and Biggs (1996) and Chan and Rao (2009) argue that education has been strongly influenced by Chinese traditions. These include values and qualities associated with what has become known as Confucian heritage cultures, such as the strong emphasis parents place on education and high expectations for students to achieve for the benefit of the whole family; a strong examination culture derived from the imperial system of selecting civil servants; the stress on practice and memorization; a deferential respect for teachers; and the virtue of modesty (Watkins and Biggs 1996).

Early international assessments, from the first tests conducted by IEA in the 1960s, right up to the TIMSS study of 1995, suggested that this synergy of Eastern and Western educational traditions was highly successful. In TIMSS 1995, Hong Kong ranked 4th in mathematics, and this success was replicated with similarly strong performance when it joined the OECD's PISA 2000 + study in 2002 (Marsh and Lee 2014). High ranking in such tests has continued in the most recent cycles of the PISA, TIMSS and PIRLS studies. The most marked change has been in reading literacy, for which Hong Kong's 4th graders improved from 14th in the 2001 cycle of PIRLS to 1st in 2011 (University of Hong Kong 2012). This performance, along with that of other 'high performing' systems in East Asia, has caught the attention of policy-makers in the West seeking to emulate their achievements (Forestier and Crossley 2015; Morris 2015).

Despite Hong Kong's longstanding high ranking in international assessments, policymakers in the immediate aftermath of the city's return to Chinese sovereignty in 1997 declared the education system was no longer fit for purpose. After reviewing the aims of education (Education Commission 1999), it was decided that radical reforms were required to upgrade both the quantity and quality of education to meet the needs of students and society in the changing local and global contexts, and the Education Commission was charged with achieving this (Tung 1997; Education Commission 2000a). While the political change was cited as one of the reasons for educational reform, the prevailing rationale revolved around the neo- liberal discourses of globalisation, competition and the need to support a post-industrial knowledge economy. The commission's blueprint for reform spelt out the global challenge:

The world is undergoing unprecedented changes, and Hong Kong is no exception. We are seeing substantial changes in the economic structure and the knowledge-based economy is here to stay. Hong Kong is also facing tremendous challenges posed by a globalised economy. (Education Commission 2000a,3)

The same document highlighted the system's weaknesses - that learning was too 'examination driven'. It went on:

School life is usually monotonous, students are not given comprehensive learning experiences with little room to think, explore and create. (Education Commission 2000a, 4)

The document identified methods of student assessment and selection as key pressure points that reinforced unnecessary practices of drilling for tests (44). Excessive competition was fuelled by an elitist system that tested and banded students for secondary places, and restricted access to Hong Kong Advanced Level study to around one-third of the age group (Curriculum Development Council, Hong Kong Examinations and Assessment Authority, and Education Bureau of the HKSAR 2013, 6). The reform 
blueprint condemns the system as one in which the success of the few 'built upon the failure of the majority of students' (Education Commission 2000a, 39).

To address the access and quality issues, the commission proposed a structure that would allow all students to complete a full six years of secondary education as well as curriculum reform that would facilitate a more in-depth learning experience and wholeperson development in the preparation for life long learning (Education Commission 2000a), along with a raft of supporting initiatives to enhance the capacity of schools and teachers to implement the reforms. The latter included new systems for school admission, school management and accountability, policy to promote integrated education and assessment for learning and new frameworks for teacher and principals' education and professional development (Curriculum Development Council, Hong Kong Examinations and Assessment Authority, and Education Bureau of the HKSAR 2013). The proposed new academic structure differed radically from the previous colonial model. Students would study three years of junior secondary education and three years of senior secondary, preparing for one single examination, the HKDSE, followed by four-year undergraduate degrees (instead of three) or other pathways that could accommodate all students wishing to continue their studies (Education and Manpower Bureau 2005; Curriculum Development Council, Hong Kong Examinations and Assessment Authority, and Education Bureau of the HKSAR 2013).

The policy bodies that led the Hong Kong reforms since the change of sovereignty constituted a mix of continuity and change from the colonial to post-colonial era (Adamson and Li 2004). They included the Education Commission, the CDC, the Curriculum Development Institute (CDI) and the HKEAA. Originally set up in 1984 to advise the colonial administration on education policy, the Education Commission had at the time a reinvigorated political mandate from the Chief Executive to consult on and propose sweeping systemic changes to meet the needs of post-retrocession Hong Kong. The HKEAA and the CDC date back to the 1970s, with the CDC advising those employed in the CDI. Together, the Education Commission, CDC and HKEAA are overseen by committees that include a mix of government representatives, community leaders, principals, teachers and academics. The level of consultation these agencies embarked on, together with the coherence of their proposals, and the planning and subsequent review and fine tuning that went into the implementation of the reforms has been praised internationally (Barber, Donnelly, and Rizvi 2012; Jensen et al. 2012; Han 2016).

We identify below how the reforms led by these agencies were informed by policies and practices from elsewhere, while international expertise assisted in the development and implementation phases. We then examine and discuss the patterns of referencing and policy borrowing that emerged.

\section{Policy borrowing in the era of reform}

Data analysis of the interviews suggests that the policy referencing and borrowing involved in Hong Kong's education reforms can be conceptualised as three intertwined strands. First, the reformers 'scanned the horizon' for other systems' policies and practices. Secondly, they worked with international agencies to monitor performance against other systems, and to benchmark the new curriculum, subject curricula and assessment standards. Hong Kong's small size, and the large flow of students to and from overseas, meant that it was necessary that its qualifications were recognised elsewhere. Thirdly, overseas experts were extensively engaged in the planning and implementation of the reforms at multiple levels across the system, either employed within the system or as consultants. Each strand is analysed in more detail below and illuminated with selected quotations transcribed from the semi-structured interviews. 


\section{'Scanning the horizon' for other systems' policies and practices}

From the outset of the reforms, reference was made to other systems. This approach reflects the policy-makers' international outlook and experience, as well as their determination that policy solutions should align with Hong Kong's needs as an international city. Policy texts highlighted the need to make 'reference to the latest trends in curriculum development around the world' (Education Commission 2000a, 66). To this end, policy-makers scanned within the East Asian region and beyond it for system and curriculum trends. The reforms of systems in Shanghai, Singapore, Taipei, Japan, Korea, Chicago and USA were referenced in Hong Kong's reform proposals (Education Commission 2000b).

A senior policy-maker cited a Chinese saying to explain the role of policy referencing at the 'horizon scanning' level: 'If you want to do something, you also need to work to know what others are doing.' But, significantly for the Hong Kong approach, she added:

Of course, we do not follow blindly. That is very important. We have to look around the major systems and digest them. (Interview, December 2013, Policymaker 1)

In other words, the policy-makers did not 'borrow', wholesale, policies and practices from other systems. They considered and 'digested' these, and adapted them for local use. A good example can be found in the features of the new senior secondary curriculum structure preparing students for the HKDSE. This structure resembles the International Baccalaureate (IB) Diploma, and shares its curriculum aims to balance breadth and depth, with the majority of students expected to study six to seven subjects, including compulsory languages (Chinese and English) and mathematics. For instance, an Independent Enquiry Study is the HKDSE's equivalent of the IB's extended essay, while the Other Learning Experiences curriculum area has strong parallels with the creativity, action and service element of the IB. As with the IB, a more enquiry-based approach to learning is envisaged, as is extensive use of school-based assessment. However, it is noteworthy that the baccalaureate style examination was not adopted in its entirety but adapted for the local context. Applied learning options were created for the less academic students, and a broader, cross-disciplinary Liberal Studies replaced the more philosophical Theory of Knowledge. In addition, a standards-referenced grading structure was adopted to reflect a wider range of academic ability in order to cater for all students, rather than merely the more academic ones that the IB was originally tailored for.

At the same time, the argument of Watkins and Biggs (2001) that some features that appear to be borrowed from the West are, in fact, complementary with Eastern traditions of education is pertinent. These include elements that focus on the wider development (including moral development) of the individual, and the readiness of teachers and students to participate in more collaborative approaches to learning that are as much derived from their more collective cultural context as progressive practices from the West. An overseas expert noted:

I think what has happened in Hong Kong (is that) they were attracted to certain things in Western research because (these) resonated with their own cultural tradition. So it's not a straightforward process of cultural borrowing. (Interview: Overseas Expert 4)

In other words, the process of policy borrowing was carefully considered. There was an understanding not only of the needs of the Hong Kong system, but also of the cultural context.

\section{Benchmarking and international recognition}

In addition to 'scanning the horizon' and adapting overseas policies and practices for the 
local context, Hong Kong policy-makers also carried out international benchmarking exercises. To this end, they used the PISA, TIMSS and PIRLS studies in a selective way, as a reference to monitor the progress of the reforms, as well as to defend and justify them in the contested policy discourse. Hong Kong's former Permanent Secretary of Education highlighted the monitoring role, after Hong Kong joined PISA in 2002:

The longitudinal and multilevel data generated by successive PISA studies will shed light on the effectiveness of our reform initiatives and identify areas where modifications and improvements may be necessary. (Law 2003)

A current policy-maker confirmed this continues to be the approach:

We take it (Hong Kong's results in international league tables) as a snapshot, one of the sources of information (of) where we can do better. (Interview, Policymaker 1)

Good results were used to promote and defend the more progressive features of the education reforms. For example, the Hong Kong Education Bureau's 2013 press release, published when the PISA 2012 findings were announced, stated:

Consistently positive results in PISA studies may suggest that the 10-year curriculum reform, which advocates learning to learn, rather than traditional textbook-based teaching, has yielded improved learning outcomes. (Education Bureau of the HKSAR (EDB) 2013)

At the same time, the focus of the authorities has been on the nuances of the findings, rather than on Hong Kong's relative position in the international league tables. For example, a leaflet on PISA co-published by the EDB (Education Bureau, the Chinese University of Hong Kong, Hong Kong Institute of Educational Research 2010) states that Hong Kong students 'can handle more effectively instruction texts than narration and argumentation'. The results are broken down to show that Hong Kong has relatively fewer students who perform at Level 5 and above, compared with other high performing countries/cities, and this is understood to be an area for improvement.

Beyond the international tests, the Hong Kong policy agencies have used multiple channels to benchmark their curriculum and assessment internationally. This benchmarking is necessitated by Hong Kong's particular context. First, international recognition for the new HKDSE is seen by policy-makers to be necessary to secure local and international confidencein thenew examination. Second, Hong Kong has had one of the highest outward student mobility rates for higher education in the world $-20.74 \%$ in 2007 , and still relatively high at 10.6\% in 2012 (UK HE International Unit 2010; UNESCO Institute of Statistics 2014). In addition, the public system has had to compete with international school and boardingschool options in providing access routes to leading universities for its students, both in Hong Kong and globally.

In this benchmarking, the UK has played a prominent role. The HKEAA drew on the colonial legacy of its long-standing relationship with the UK examination awarding body Cambridge International Examinations (CIE), and invited it to conduct similar benchmarking activities for the HKDSE against British examinations as it had done for the predecessors, the Hong Kong Certificate of Secondary Education and Hong Kong Advanced Level examinations. And, rather than developing its own system of assessment for foreign languages, the HKEAA contracted the CIE to administer six 'Other Language' subjects in the HKDSE (classified in the HKDSE as 'Category C' subjects) and used its ASlevel products for their examination. The HKEAA also commissioned the UK's university central admissions agency UCAS and the UK National Recognition Information Centre to compare the HKDSE with UK Advanced Levels, for recognition for higher and postsecondary education and student admission purposes in the UK (HKEAA 2015). 
The authorities' approach is not without criticism. A number of the stakeholders who we interviewed noted how these benchmarking and international recognition exercises may have restricted local policy control. For example, benchmarking resulted in the requirement of a minimum number of learning hours per subject, and this could not be easily accommodated in the new curriculum framework that had sought to broaden the curriculum to involve more subjects and academic and non-academic learning experiences. It also meant the imposition of standards that were not suitable to the full complement of students taking the exam. Interviewee Principal 2, for example, reflected there had been 'too much concern' for recognition, at the expense of recognising the learning of less academic students that did not match the profile of the international benchmarks for higher education that the grading system is pegged against.

Whatever the case may be, we argue that the benchmarking of the curriculum and assessment, and the measured and nuanced approach to international tests, can be identified as two characteristics distinctive of Hong Kong's approach to referencing and policy borrowing.

\section{Engaging international expertise}

The third characteristic of the Hong Kong approach to policy referencing and borrowing is the direct engagement with international expertise to influence reforms. In this, Hong Kong policy-makers have appeared to learn from the weaknesses of previous top-down approaches to reform, such as the Target Oriented Curriculum (TOC) developed in the 1990s from Australian, New Zealand and Scottish models of task-based curriculum and standardsreferenced assessment. Principals and teachers were not convinced of the value and relevance of the TOC in the highly competitive local context in which practitioners and parents perceived that summative tests and examinations had to take precedence over formative assessment (Education Commission 2000a; Watkins and Biggs 2001).

In the recent reforms, the strategy was to avoid a top-down approach. Instead, the policy development and implementation process emphasised partnerships with wider networks, including extensive engagement with local and international experts. This intent was made clear in the blueprint for the reforms:

[The Curriculum Development Institute will] pool the wisdom of local and international experts in curriculum development, teaching research, assessment, evaluation and different learning areas through constant exchanges of experiences. (Education Commission 2000a, 66)

The international experts who were consulted often drew on policies and practices in their home country. In this, the borrowing that took place was primarily channelled to support implementation in specific curriculum areas. The CDC spelt this out in the 'Learning to Learning' curriculum blueprint:

A global community of partners can be formed for specific areas: learning and teaching; critical thinking and creativity; assessment for learning; curriculum planning for each KLA (Key Learning Area); moral and civic education; curriculum change and evaluation. (Curriculum Development Council 2001, 115)

In other words, overseas experts were engaged not primarily to legitimise the reforms, but rather to provide specific technical expertise after the broad direction of the reforms had been identified. These inputs included contributing to the design and implementation of the new curriculum, assessment and quality assurance models, and providing action research and seed projects piloting and evaluating curriculum and pedagogical innovations with schools as well as monitoring the outcomes of the reforms (e.g. McGaw 2006; Elliottand Yu 2008). The collaborative process was designed to develop 
the capacity of local stakeholders - especially teachers, curriculum officers and school inspectors - and go beyond the largely symbolic efforts of earlier reforms such as the TOC (Morris and Adamson 2010; Lee 2014).

Through these international channels, as well as the participation and influence of its own now well-established academic community, Hong Kong can be seen as becoming a hub for the type of 'lively international traffic in educational ideas and practices' that Alexander $(2001,508)$ observed had happened across the globe for centuries. There is the active involvement of what can be seen as examples of 'travelling reformers' (Steiner-Khamsi 2010), or a 'guiding coalition' of reformers (Barber 2007), and 'system thinkers' (Levin and Fullan 2008). But what was most noticeable was the sustained engagement, in Hong Kong, of overseas experts to support the planning and implementation of the reforms. The education features borrowed included: the discourse on 'learning to learn' that has parallels with the ESRC Teaching and Learning Research Programme 'Learning How to Learn' (see James et al. 2006; of which several of the authors were engaged in Hong Kong consultation activity); policy initiatives to promote assessment for learning (Black and Wiliam 1998; James et al. 2006) (with the support of English expertise); school-based management (Chapman 1990; Abu-Duhou 1999) (that drew on the experience of the Australian state of Victoria); an accountability model based on a mix of external school review and school self evaluation from Scotland (see MacBeath 1999 and MacBeath and McGlynn 2003); as well as elements of the IB Diploma for the HKDSE (Berry and Adamson 2012; IBO 2016).

Overseas experts, including academics, worked alongside experts from Hong Kong. The UK was an important source of influence, in part because of long-established relationships and collaboration between UK educationists and their Hong Kong counterparts during the colonial era. One senior policy-maker noted this was the case

Because of our knowledge [of their work] from the university, [and] because we worked together. They [the overseas experts] are not strangers to us. (Interview: Policymaker 1, December 2013)

However, the UK was not the only source of Hong Kong's interests in overseas policies and practices. Even while it was a British colony, Hong Kong had looked around the world for ideas and inspiration, such as from Australia and Canada. More recently it has also looked to Mainland China. The main, if not sole criterion, for referencing appears to be shared views, including a common understanding of education and how it should be reformed to enhance student learning. The stakeholders who were interviewed saw the collaboration that went on as an effective approach to borrowing, with the dynamic underpinned by the increased knowledge and professionalism of local officials, principals and teachers, and the potential for two-way exchange. Notably, stakeholders with experience of other systems saw the Hong Kong approach to policy referencing and borrowing as distinctive.

Hence, our data suggest that the third element in the Hong Kong approach to policy referencing and borrowing is engagement with overseas and local experts and stakeholders, informed by a respect for academic research, as well as for the experiences of principals and teachers. The system was informed by local education experts, with key policy-makers drawn from an academic background.

\section{Outcomes of the reforms}

The previous sections describe how recent education reforms in Hong Kong included an approach to policy referencing and borrowing that involved horizon scanning, benchmarking and international recognition, and direct engagement with international expertise. Early successes of the reforms are evident. For the first time, there were school places for all students to complete senior secondary schooling, in contrast to the old system 
that could cater for only about one-third of the cohort in the final two years. Actual retention rates of students who entered Secondary 1 and completed Secondary 6 have increased to around 86\%, based on our analysis of student enrolment data from 2009 to 2014 (Census and Statistics Department 2015). In addition, school survey data show that, by $2014,86 \%$ of students continued to post-secondary education, including 34\% progressing to undergraduate study locally and overseas (Curriculum Development Council, Hong Kong Examinations and Assessment Authority and Education Bureau of the HKSAR 2015, 50). Furthermore, the curriculum is now more closely aligned with approaches policy-makers advocated for formative and summative assessment, as reflected in the emphasis on vertical continuity between stages and lateral coherence across disciplines, recommended in Learning to Learn (ibid, 73). However, not all reform measures have been implemented as intended. For example, policy-makers have been forced to reduce their ambitions for school-based assessment in the face of local resistance and concerns that in the Hong Kong context this exacerbated work- load, rather than achieved the ideals of assessment for learning (Berry and Adamson 2012; Curriculum Development Council, Hong Kong Examinations and Assessment Authority and Education Bureau of the HKSAR 2015).

From the perspective of the school principals interviewed, the schools accountability framework that features a mix of self-evaluation and external review, which was developed with some input from academics and the school inspectorate from Scotland, has been the most successful example of policy borrowing, despite resistance that contributed to public protest in the early years (Forestier 2006). This accountability system was perceived by school stakeholders as being generally fair and supportive of school improvement. It was described by one principal as first focusing on the strengths of schools, and celebrating these, before focusing on how they could be improved. This supportive role was enhanced by the inclusion of principals from other schools on review panels, allowing for the sharing of good practices. Unlike the school inspection system used in England which the Hong Kong policymakers regarded as a negative lesson - reports on individual schools were not published, or followed up by the implementation of special measures, and the accountability system was not used to force changes to the governance and leadership of schools identified as performing below the required standards.

Despite the considered approach adopted by policy-makers to the reforms, stakeholders could see limitations in trying to adopt other policies and practices from elsewhere. These included suitability for the local context, and limited impact on classroom culture, as well as some negative consequences. Principal 2 said:

We have the form, but I am still asking do we have the substance or spirit yet? We have a new structure to let students have more space to learn, to choose subjects which they like, which fit their potential and intelligences better. But schools are moving back to the academic kind of track because of university admissions and exams; it is now about choosing the right kind of subjects which will enable more students to go to university so schools can improve their record to attract parents in. It is as real as death. (Interview, Principal2, December 2013)

The role of the overseas expert in Hong Kong's reforms may now be changing. Over the course of the research, we observed that there appeared to be fewer employed within the system or acting as consultants compared with a decade ago during the planning and early implementation of the reforms. Meanwhile, the Hong Kong government has actively promoted more study visits - for teachers and students - to Mainland China (Leung 2015). At the same time, the Education Commission and the professional civil service, a legacy of the colonial model, have also seen their influence decline after a new political system was put in place in 2004 involving political appointees to head government bureaux (Morris 2010). This may be the natural outcome of the process of decolonisation from the UK, and 'recolonization' by China (Lo 2007), as well as the 
growing indigenous strength of the local education community. The approach to referencing and borrowing described in this article is therefore notstatic, but is changing according to Hong Kong's changing needs for expertise and referencing, and the evolving political context.

Hong Kong also offers a model in balancing the dichotomies evident in competing educational ideologies. As Overseas Expert 1 explained:

I think Hong Kong, probably more than any [system], in terms of the sort of ConfucianSocratic values, ... has really tried and said, 'We need to do both' ... There is evidence that what Hong Kong has done is actually, first of all, had the vision that they needed to change, that they needed to be aware of pressures on them from Mainland China, and also the rest of the world, and where they wanted to position themselves. So they had to have that kind of situational analysis. Then they knew that it was going to be a long process and they would have to involve a lot of people in that, including academics, including advisors from elsewhere. I think they've got a pretty good intelligence system to find out where those people are ... They bring them in and they test them, and they reject some and keep with others. And I think they also know that developing a system is complex; [it] has a number of components, ... with all the systems having to reinforce one another. The other thing I've been really impressed with in Hong Kong is the extent to which they've consulted, and really taken that seriously ... at every moment. (Interview, Overseas Expert 1)

Overseas Expert 4 argued that, despite the limitations in democracy at the political level in Hong Kong, the authorities have gone about education reforms in a more democratic manner than has been seen in England.

If anything is to be borrowed, it's basic ideas that you might link with, well, I call it democratic rationality. So working things out by involving people in partnerships and in discussion and dialogue, crossing different interest groups ... We [in England] are trying to think out policymaking structures in this country that are a bit like the [multi-stakeholder] Education Commission in Hong Kong. (Interview, Overseas Expert 4, February 2014)

\section{Discussion and conclusion}

Our examination of the recent education reforms reveals the distinctive features in Hong Kong's approach to policy referencing and borrowing. This is one that is characterised by three main elements. First, the authorities 'scan the horizon' for policies and practices, and seek to draw nuanced lessons from these. Second, they use international assessments among other sources to monitor and benchmark the new system, and obtain international recognition. Third, there is engagement with local and overseas experts, and a concerted effort to ensure that lessons learned were appropriate for the Hong Kong context.

This approach to policy referencing and borrowing is underpinned by a number of features. Reforms started with an examination of the fundamentals - the aims of education focused on student learning in the context of changing local needs and global trends, and a blueprint to achieve these. Following this, overseas as well as local experts (including academics and teaching practitioners) were consulted, and their technical expertise sought, on aspects of the education system. The process also involved extensive consultation with stakeholders, such as teachers, parents and employers. The complex reforms took a decade to plan, develop and implement. During this process, there was an attempt to balance dichotomies within the system. There was also effort to coordinate the different aspects of the system, including school support, leadership and teacher development.

The extent of the referencing and borrowing of educational policies and practices in the recent reforms reflects the increasing speed of policy transfer in the context of globalisation (Crossley and Watson 2003; Steiner-Khamsi 2010). In addition, it reveals 
forces of continuity and change in the transition from British to post-colonial rule in the manner it built on previous reforms derived from Western models and the actors and institutions involved.

Referencing and borrowing by Hong Kong, with the direct involvement of overseas academic experts, has played multiple functions to inform and model reforms on the one hand, and justify and defend them on the other. While on onelevel it contributed to what Rappleye (2012) describes as the theatre of politics, the multiple levels of engagement with overseas practices and ideas went deeper, beyond promoting policy intentions, to facilitating the implementation of policy actions. The latter was achieved through its selective use of referencing and borrowing to support a locally initiated reform, involving a process of indigenisation, the latter aligning with Phillips and Ochs' four-stage model of borrowing (2003). Nonetheless, there have been limitations in the outcomes that have emerged in Hong Kong, and these affirm the challenges in transferring policies and practices from one context to another as well as some elements of a dependency culture borne out of its recent colonial past. However, Hong Kong policy-makers have been notable in their understanding of these limitations, the measures they took to adapt imported ideas to the local context and the networks they deployed to implement educational change at multiple levels. There was also a determination to resolve dichotomies between East and West and the so-called traditional and progressive approaches to education, and to work through collaborative networks that bridge policy, practice and academia.

These features of the Hong Kong approach impressed the 'travelling experts' or reformers. Indeed, many returned to their home countries believing that some elements of the Hong Kong approach to policy borrowing and referencing were distinctive and contrasted markedly with the approaches prevalent in their own systems, and provided lessons which could be usefully learnt. The distinctiveness that they focused on related to the process, rather than the specific nature, of the reforms, which began with an investigation of the aims of education and continued with a strong degree of collaboration between policy-makers, practitioners and academics. These reflections are consistent with numerous portrayals of the process of policy borrowing in England, which describe the approach there as a highly expedient and opportunistic enterprise designed to legitimise a preferred policy direction (e.g. Alexander 2012; Morris2012; You and Morris 2015).

The readiness of Hong Kong policy-makers to look outward and engage hands-on expertise has arguably paid dividends in its reform efforts. An internationally recognised qualification is in place and progress has been made on the implementation of a more balanced curriculum that gives schools and teachers more space to vary their teaching approaches. The on-going review and fine-tuning of the curriculum and assessment provide a structure to address issues - including challenges from borrowing - as they emerge (Curriculum Development Council, Hong Kong Examinations and Assessment Authority and Education Bureau of the HKSAR 2015).

\section{Acknowledgements}

The authors appreciate the support of the University of Bristol Graduate School of Education Doctor of Education programme in the preparation of this article.

\section{Disclosure statement}

Katherine Forestier, Bob Adamson, Christine Han and Paul Morris acknowledge they have received no financial interests or benefits arising from the direct applications of their research. 


\section{Funding}

This work was supported by the Economic and Social Research Council (UK)/Research Grants Council (Hong Kong) Joint Research Funding Scheme [grant number Project ES/K010433/1].

\section{References}

Abu-Duhou, I. 1999. School Based Management. Paris: International Institute of Education Planning, UNESCO. Adamson, B., and S.-P. Li Titus. 2004. "Primary and Secondary Schooling." In Education and Society in Hong Kong and Macao: Comparative Perspectives on Continuity and Change, edited by M. Bray and R. Koo, 35-60. Hong Kong: Comparative Education Research Centre, The University of Hong Kong. Alexander, R. J. 2001. "Border Crossings: Towards a Comparative Pedagogy." Comparative Education 37 (4): 507-523.

Alexander, R. J. 2012. "Moral Panic, Miracle Cures and Educational Policy: What Can We Really Learn from International Comparison?” Scottish Educational Review 44 (1), 4-21.

Auld, E., and P.Morris. forthcoming. "PISA, Policy and Persuasion: Translating Complex Conditions into Education "Best Practice"." Comparative Education. doi: http://dx.doi.org/10.1080/03050068.2016. 1143278

Ball, S. 2008. "New Philanthropy, New Networks and New Governance in Education." Political Studies 56, 747765.

Barber, M. 2007. Instruction to Dlieber. London: Politico, Methuen.

Barber, M., K.Donnelly, and S. Rizvi. 2012. OceansofInnovation: TheAtlantic, the Pacific, GlobalLeadership and the Future of Education. London: Institute of Public Policy Research.

Berry, R., and B. Adamson. 2012. "AssessmentReform in Hong Kong Schools." SA-EDUCJournal 9 (1), 1-11. Black, P., and D. Wiliam. 1998. "Assessment and Classroom Learning." Education: Principles, Policy and Practice 5 (1), 7-74.

Census and Statistics Department of the HKSAR. 2015. “Hong Kong Annual Digest of Statistics.” Accessed February 9, 2016. www.statistics.gov.hk/pub/B10100032015AN15B0100.pdf.

Chan, Carol K. K., and N. Rao. 2009. "The Paradoxes Revisited: The Chinese Learner in Changing Educational Contexts." In Revisiting the Chinese Learner: Changing Contexts, Changing Education, edited by C. K. K. Chan and N. Rao, 315-349. Rotterdam and Hong Kong: Springer/Comparative Education Research Centre, The University of Hong Kong.

Chapman, J., ed. 1990. School Based Decision Making and Management. London: Falmer Press. Crossley, M., and K. Watson. 2003. Comparative and International Research in Education-Globalisation,Context and Difference. Abingdon: RoutledgeFalmer.

Curriculum Development Council. 2001. "Learning to Learn - The Way Forward in Curriculum Development." Web edition. Accessed May 23, 2013. http://www.edb.gov.hk/en/curriculum- development/cscurriculum-doc-report/wf-in-cur/index.html

Curriculum Development Council, Hong Kong Examinations and Assessment Authority, and Education Bureau of the HKSAR. 2013. The New Senior Secondary Learning Journey - Moving Forward to Excel: Progress Report on the New Academic Structure Review. Hong Kong: Government Printer.

Curriculum Development Council, Hong Kong Examinations and Assessment Authority and Education Bureau of the HKSAR. 2015. Continual Renewal from Strength toStrength-Reporton the NewAcademic Structure Medium-Term Review and beyond.http://334.edb.hkedcity.net/EN/334_review.php.

Department for Education. 2010."The Importance of Teaching the Schools White Paper 2010 London: The Stationery Office Limited on Behalf of the Controller of Her Majesty's Stationery Office." https:// www.gov.uk/government/uploads/system/uploads/attachment_data/file/175429/CM-7980.pdf.

Department for Education. 2011. The Frameworkfor the National Curriculum. A Report by the Expert Panel for the National Curriculum Review. London: Department for Education.

Education Bureau of the HKSAR (EDB). 2013. Press Release: 'International Study Shows Hong Kong Students' Reading, Mathematical and Scientific Literacy Continue to Rank among the World's Best'. December 3, 2013. Accessed February 9, 2016. http://www.info.gov.hk/gia/general/201012/07/ P201012070191.htm

Education Bureau, the Chinese University of Hong Kong, Hong Kong Institute of Educational Research. 2010. How WellDoes Hong Kong'sEducation Work? Pisa2009(Leaflet). Hong Kong: GovernmentPrinter. Education Commission, Hong Kong Special Administrative Region of China. 1999. Education Blueprintfor the 21st Century: Review of the Academic System Aims of Education. Hong Kong: Government Printer.

Education Commission, Hong Kong Special Administrative Region of China. 2000a. Learning for Life, Learning through Life, Reform Proposals for the Education System in Hong Kong. September. Hong Kong: Government Printer.

Education Commission, Hong Kong Special Administrative Region of China. 2000b. Review of Education System: Reform Proposals Consultation Document. Hong Kong: Government Printer.

Education and Manpower Bureau of the HKSAR. 2005. The New Academic Structure for Senior Secondary Education and Higher Education - Action Plan for Investing in the Future of Hong Kong. Hong Kong: Government Printer.

Elliott, J., and W. M. C. Yu. 2008. Learning Studies as an Educational Change Strategy in Hong Kong: An Independent Evaluation of the "Variation for the Improvement of Teaching and Learning"(VITAL). Hong Kong: Hong Kong Institute of Education.

Forestier, K. 2006. “Suicides Spark Staff Protests.” TES. Accessed May 11, 2008. www.tes.co.uk/article. 
aspx?storycode $=2184046$.

Forestier, K. 2011. TeacherEducation and Education-related Studies in Relation to Hong Kong. Hong Kong: British Council, for the Education UK Partnership.

Forestier, K., and M. Crossley. 2015. "International Education Policy Transfer- Borrowing Both Ways: The Hong Kong and England Experience." Compare: A Journal of Comparative and International Education 45 (5): 664 685.

Gove, M. 2012. Speech to the Education World Forum. http://www.education.gov.uk/inthenews/ speeches/a0072274/michael-gove-to-the-education-world-forum.

Han, C. 2016. "External Policy Referencing in Education." In Education, Ethics and Experience: Essays in Honour of Richard Pring, edited by M. Hand and R. Davies, 135-148. London: Routledge.

HKEAA (Hong Kong Examinations and Assessment Authority). 2015. Benchmarking Studies on International Examinations. Accessed July 31, 2015. http://www.hkeaa.edu.hk/en/recognition/ benchmarking/

IBO (International Baccalaureate Organisation). 2016. Diploma Programme. Accessed Febrary 8, 2016. http://www.ibo.org/programmes/diploma-programme/.

James, M., P.Black, P.Carmichael, C. Conner, P.Dudley, A. Fox, D. Frost, et al. 2006. Learning How to Learn: Tools for Schools. Improving Practice (TLRP). London: Routledge.

Jensen, B., A. Hunter, J. Sonnemann, and T. Burns. 2012. Catching up: Learning from the Best School Systems in East Asia. Melbourne: Grattan Institute.

Kamens, D. H. 2013. "Globalisation and the Emergence of an Audit Culture: PISA and the Search for 'Best Practices' and Magic Bullets." In PISA, Power and Policy: The Emergence of Global Educational Governance, edited by H. D. Meyer and A. Benavot, 7-26. Didcot: Symposium. 117-139.

Law, Fanny Fan C.-F. 2003. Speech to the PISA International Conference: 'What Do the PISA Results Tell Us about the Education Quality and Equality in the Pacific Rim?' http://www.info.gov.hk/gia/ general/200311/21/1121146.htm.

Lee, J. 2014. "Curriculum Reforms in Hong Kong: Historical and Changing Socio-Political Contexts." In Asia's High Performing Education Systems: The Case ofHong Kong, edited by C. Marsh and J. Lee, 17-32. NewYork, NY: Routledge.

Leung, C. Y. 2015. 2015 Policy Address. http://www.policyaddress.gov.hk/2015/eng/.

Levin, B., and M. Fullan. 2008. "Learning about System Renewal." Education Management Administration and Leadership 36, 289-303. British Educational Leadership, Management \& Administration Society. Lo, S. 2007. "The Mainlandization and Recolonization of Hong Kong: A Triumph of Convergence over Divergence with Mainland China." In The Hong Kong Special Administrative Region in Its First Decade, edited by Joseph Y .S. Cheng, 179-232. Hong Kong: City University of Hong Kong Press.

MacBeath, J. 1999. Schools Must Speakfor Themselves: Arguments for School Self-evaluation (Whats in It for Schools?). Abingdon: Routledge.

MacBeath, J., and A. McGlynn. 2003. Self-evaluation. What's in It for Schools? London: Falmer.

Marsh, C., and J. Lee. 2014. "Asia's High Performing Education Systems: The Case of Hong Kong - Introduction." In Asia's High Performing Education Systems: The Case of Hong Kong - Introduction, edited by C. Marsh and J. Lee, 1-13. New York, NY: Routledge.

McGaw, B. 2006."An International View of Hong Kong's Education Reform." Presentation to Hong Kong Education Commission Reporting Session on Reform - 2006. http://www.e-c.edu.hk/eng/reform/ Prof\%20Barry\%20McGaw\%20Speech.pdf.

Meyer, H. D., and A.Benavot. 2013."PISA and the Globalization of Education Governance: Some Puzzles and Problems." In PISA, Power and Policy: The Emergence of Global Educational Governance, edited by

H. D. Meyer and A. Benavot, 7-26. Didcot: Symposium.

Morris, P.2010. "Academic Freedom, University Governance and the State: The Commission of Inquiry into the Hong Kong Institute of Education." Journal of Education Policy 25 (5), 587-603.

Morris, P.2012. "Pick 'n' Mix, Select and Project; Policy Borrowing and the Quest for 'World Class' Schooling: An Analysis of the 2010 Schools White Paper." Journal of Education Policy 27 (1): 89-107. doi:http://dx.doi.org/10.1080/02680939.2011.596226.

Morris, P.2015. “Comparative Education, PISA, Politics and Educational Reform: A Cautionary Note." Compare: A Journal of Comparative and International Education 45 (3): 470-474. doi:http://dx.doi.or g/10.1080/03057925.2015.1027510.

Morris, P., and B. Adamson. 2010. Curriculum, Schooling and Society in Hong Kong. Hong Kong: Hong Kong University Press.

Oates, T. 2013. "Using International Comparisons to Refine the National Curriculum." A speech by Tim Oates, Group Director of Assessment Research and Development, Cambridge Assessment, to the Mayor's Education Conference, November. http://www.cambridgeassessment.org.uk/news/using- internationalcomparisons-to-refine-the-national-curriculum/.

OECD (Organisation for Economic Co-operation and Development's). 2014. PISA 2012 Results: What Students Know and Can Do-Student Performance in Mathematics. Reading and Science. Vol. I. Rev. Ed. February. Paris: OECD Publishing. doi:http://dx.doi.org/10.1787/9789264201118-en.

Ofqual (Office of Qualifications and Examinations Regulation). 2012. International Comparisons in Senior Secondary Assessment - Full Report. Crown Copyright. https://www.gov.uk/government/uploads/ system/uploads/attachment_data/file/372211/2012-06-12-international-comparisons-in-seniorsecondary-assessment.pdf. 
Ozga, J. 2000. Policy Research in Educational Settings: Contested Terrains. Buckingham: Open University Press.

Perry, L., and D.-H. Tor. 2009. "Understanding Educational Transfer: Theoretical Perspectives And Conceptual Frameworks." Prospects 38: 509-526.

Phillips, D., and K. Ochs. 2003. "Processes of Policy Borrowing in Education: Some Explanatory and Analytical Devices." Comparative Education 39 (4): 451-461.

Raffe, D., and K. Spours. 2007."Three Models of Policy Learning and Policy-Making in 14-19 Education." In Policy-Making and Policy Learning in 14-19Education, edited by D. Raffe, and K. Sours, 1-32. Bedford Way Papers, London: IoE London.

Rappleye, J. 2012. "Reimagining Attracting and 'Borrowing' in Education - Introducing a Political Production Model." In World Yearbook of Education 2012 - Policy Borrowing and Lending in Education, edited by G. Steiner-Khamsi and F. Waldow, 121-147. Abingdon: Routledge.

Ritchie, J., and L. Spencer. 1994. "Qualitative Data Analysis for Applied Policy Research." In Applied Qualitative Research, edited by Alan Bryman and Roger E. Burgess, 173-194. London: Routledge.

Sellar, S., and B. Lingard. 2013."Looking East: Shanghai, PISA 2009 and the Reconstitution of Reference Societies in the Global Education Policy Field." Comparative Education 49 (4): 464-485.

Steiner-Khamsi, G. 2002. "Re-framing Educational Borrowing as a Policy Strategy." In Internationalisierung Internationalisation, edited by Marcelo Caruso and Heinz-ElmarTenorth, 57-89. Frankfurt/M: Lang. SteinerKhamsi, G. 2010. "The Politics and Economics of Comparison." Comparative Education Review 54 (3): 323342.

Sweeting, A. 2004. Education in Hong Kong, 1941 to 2001 Visions and Revisions. Hong Kong: Hong Kong University Press.

Tung, C. H. 1997. "Building Hong Kong for a New Era." Policy Address. http://www.policyaddress.gov. $\mathrm{hk} / \mathrm{pa} 97 /$ english/patext.htm.

UK HE International Unit. 2010. International, Summer 2010. Higher Education in Facts and Figures. London: UK Higher Education International Unit.

UNESCO Institute of Statistics. 2014. "Global Flow of Tertiary-level Students." http://www.uis.unesco. org/Education/Pages/international-student-flow-viz.aspx.

University of Hong Kong. 2012. Press Release: The Progress in International Reading Literacy Study (PIRLS) International Report: Hong Kong Section. http://www.hku.hk/press/news_detail_8975.html.

Vidovich, L. 2007. "Removing Policy from Its Pedestal: Some Theoretical Framings and Practical Possibilities." Educational Review 59 (3): 285-298.

Waldow, F. 2012. Standardisation and Legitimacy: Two Central Concepts in Research on Educational Borrowing and Lending World Yearbook ofEducation 2012 - Policy Borrowing and Lending in Education, 411-427. Abingdon: Routledge.

Watkins, D. A., and J. B. Biggs, eds. 1996. The Chinese Learner: Cultural, Psychological, and Contextual Influences. Hong Kong: Comparative Education Research Centre, University of Hong Kong.

Watkins, D. A., and J. B. Biggs, eds. 2001. Teaching the Chinese Learner: Psychological and Pedagogical Perspectives. Hong Kong: Comparative Education Research Centre, University of Hong Kong.

You, Y., and P.Morris. 2015. "Imagining School Autonomy in High-performing Education Systems: East Asia as a Source of Policy Referencing in England." Compare: A Journal of Comparative and International Education, 1-24. doi:http://dx.doi.org/10.1080/03057925.2015.1080115. 